\title{
Optimization of Fermentation Factors for Vinegar Preparation from Sugarcane Jaggery using Response Surface Methodology
}

Vishal Lohan, Kanika Pawar, Anju Kumari, Rakesh Gehlot

10.18805/ajdfr.DR-1730

\begin{abstract}
Background: Vinegar, an acidic functional fermentation product and known for its diverse health benefits was developed using liquid jaggery. A study was conducted to standardize the method of vinegar production from liquid jaggery using two different sugarcane varieties viz., $\mathrm{CoH} 160$ and $\mathrm{Co89003.}$

Methods: The submerged fermentation of liquid jaggery was carried out using yeast Saccharomyces cerevisiae and vinegar was produced using Acetobacter aceti. For the computation analysis of an optimized solution, a central composite rotatable design was applied which constituted three variables temperature $\left({ }^{\circ} \mathrm{C}\right)$, inoculum concentration $(\%)$ and incubation time (days) and its influence on acetic acid percent as an important response was studied using Response Surface Methodology. Overall, twenty experimental trials were conducted as well as assessed on the vinegar quality indexes.

Result: Vinegar prepared with 7.5 per cent inoculum concentration, incubated for a fermentation period of 12.5 days at $28.5^{\circ} \mathrm{C}$ was selected due to maximum acetic acid concentration achieved $(>3.5 \%(\mathrm{w} / \mathrm{v})$. The optimized vinegar contained total soluble solids (4.55-4.75 ${ }^{\circ}$ Brix), reducing sugar (0.26-0.29\%), total sugars (2.7-2.8\%), titratable acidity (4.72-5.10\%), pH (4.28-4.52), ascorbic acid (17.64-19.97\%), alcohol content (0.68-0.79\%), acetic acid (3.52-3.83\%) and total phenols $(36.69-38.22 \mathrm{mg} / 100 \mathrm{ml})$. The liquid jaggery vinegar had a bright yellow- brown color, cane flavor and vinegar aroma. It was found organoleptically acceptable.
\end{abstract}

Key words: Liquid jaggery, Optimization, Response surface methodology, Sugarcane, Vinegar, Wine.

\section{INTRODUCTION}

Vinegar a fermented aqueous product, with unique sour and tart flavor and is used as an excellent ingredient for variety of food preparations, salad dressings, ketchup, hot sauce. It is also prepared from diverse substrates such as fruits, malted barley or other cereals, hydrolyzed cereals, starches, sugar solution, molasses, jaggery, sugarcane juice etc. with or without added spices or caramel (Adebayo-Oyetoro et al., 2017). It is an age long preservative and condiment used since centuries. Food cooked in natural vinegar has a good shelf life because it inhibits the growth of micro-organisms by reducing the $\mathrm{pH}$ of food products to a level. It has a huge demand for its industrial production using cheap substrate material. Vinegar has multiple health benefits which is mainly due to its bioactive compounds (melanoidins, fructooligosaccharides, phenolic compounds, minerals, vitamins and a-glucan), antioxidant and antimicrobial potential, affecting physiological activities like improving digestive system, stimulating appetite, preventing inflammation and hypertension, lowering serum cholesterol, triacylglycerols and lessen glycemic index (Chen et al., 2015).

Sugarcane is a prime yield in Northern India and its extract is a substrate of choice for natural vinegar as a result of its high sugar content and accessibility (Kocher et al., 2006). Vinegar is being produced from sugarcane juice in Philippines, some parts of India like Punjab and Southern parts of India, but its production from liquid jaggery have not been reported so far. Liquid jaggery is semi-liquid syrup, natural sweetener obtained from sugarcane juice. It is having
Centre of Food Science and Technology, Chaudhary Charan Singh Haryana Agricultural University, Hisar-125 004, Haryana, India.

Corresponding Author: Kanika Pawar, Chaudhary Charan Singh Haryana Agricultural University, Regional Research Station, Karnal132 001, Haryana, India. Email: kanikapawar@gmail.com

How to cite this article: Lohan, V., Pawar, K., Kumari, A. and Gehlot, R. (2022). Optimization of Fermentation Factors for Vinegar Preparation from Sugarcane Jaggery using Response Surface Methodology. Asian Journal of Dairy and Food Research. DOI: $10.18805 /$ ajdfr.DR-1730.

Submitted: 22-05-2021 Accepted: 07-12-2021 Online: 17-01-2022

40 to 60 per cent sucrose, 30 to 36 per cent water, 15 to 25 percent invert sugar and also rich in important vitamins and minerals (Nath et al., 2015). The micronutrients which are present in jaggery have many nutritional and medicinal aspects such as it is anti-carcinogenic and antitoxic activity, produce heat and give instant energy to a human body (Kumar and Singh, 2020). Now-a-days, brewed vinegars are gaining popularity as compared to synthetic vinegar which is derived from petroleum residues that are harmful to human health. Presently vinegar is being produced from a lot of substrates, using sugarcane as a source of jaggery production is also prevalent, but it often faces fermentation during storage and mass production, thus suffers losses. Hence vinegar preparation from liquid jaggery will provide cheaper, healthier and nutritious option with fresh taste, unique flavor and aroma. Moreover, high sugar content and lower shelf life which is due to its high moisture content 
makes it a good medium for vinegar production. More than 70 per cent of world jaggery is being produced in India, but suffers from business losses (Singh et al., 2011). An attempt was therefore, made to standardize the method of vinegar production from liquid jaggery using two different sugarcane varieties through Central composite rotatable design (CCRD) so as to optimize the process parameters in lieu of maximum acetic acid content and thereafter, the good sensory acceptability.

\section{MATERIALS AND METHODS}

The research work was carried out in Centre of Food Science and Technology, CCS Haryana Agricultural University, Hisar and Regional Research Station, Karnal during the year 20192020. Two early sugarcane varieties, namely CoH 160 and Co89003 were selected as source materials from Regional Research Station, Karnal, Haryana. To extract fresh sugarcane juice (18-20 Brix) from sugarcane stalks, mechanical crusher was used. All media and chemical solutions used in the analysis of jaggery, wine and vinegar were of good quality and analytical grade.

\section{Liquid jaggery}

The clear extracted juice was clarified and filtered using okra mucilage. The preheating $\left(75-80^{\circ} \mathrm{C}\right)$ of sugarcane juice is followed by concentration of juice done by boiling at 103$106^{\circ} \mathrm{C}$. Finally, semi-liquid syrup (liquid jaggery) was cooled and stored in bottles for its further processing into the vinegar. Total soluble solids (TSS) of the liquid jaggery was measured with hand refractometer (using 58-90 Brix) expressed as per cent soluble solids.

\section{Micro-organisms used}

The fermentation yeast Saccharomyces cerevisiae (MTCC 4787) and Acetobacter aceti (MTCC 2945) were collected from the Institute of Microbial Technology, Chandigarh, Punjab, India. In this study, both microorganisms were used to carry out the submerged fermentation (Chen et al., 2015) method for preparation of vinegar from liquid jaggery. Thus, double fermentation (alcoholic and acetous fermentation) was carried out during the vinegar production from liquid jaggery. The ethanol was produced by yeast (Saccharomyces cerevisiae), during fermentation under anaerobic conditions, while it is further converted to acetic acid (acetification) by acetic acid bacteria (Acetobacter aceti) under aerobic conditions. The detailed process is explained below.

\section{Wine (Alcoholic fermentation)}

Liquid jaggery $\left(68^{\circ} \mathrm{Brix}\right)$ was pasteurized and cooled. It was further diluted to desired total soluble solids $\left(20^{\circ} \mathrm{Brix}\right)$ as suggested by Ribeiro et al., 2015. Potassium metabisulphite @ 100 ppm was added and left for $48 \mathrm{~h}$. To carry out the alcoholic fermentation the pitching of the liquid jaggery was done by the addition of 10 per cent (v/v) yeast Saccharomyces cerevisiae inoculum maintained on yeast extract peptone dextrose (YEPD) medium and then incubated at $28^{\circ} \mathrm{C}$ for 14 days. Observations were carried out till steady state total soluble solids were obtained. After that, decanting in bottles was done and agar bentonite $(2: 1)$ @ $200 \mathrm{ppm}$ was added in wine at $4-5^{\circ} \mathrm{C}$ for $3-4$ days. Thereafter, siphoning and bottling was done.

\section{Adjustment of alcohol in wine}

Partially clarified wine prepared from liquid jaggery of both the sugarcane varieties ( $\mathrm{CoH} 160$ and Co89003) were found to have 8.8 per cent $(\mathrm{w} / \mathrm{v})$ and 8.0 per cent $(\mathrm{w} / \mathrm{v})$ alcohol content, respectively and the results are in agreement with Ribeiro et al., 2015 and Oliveira et al., 2018. Before proceeding for acetous fermentation, wine was diluted with water in $1: 1$ ratio so that the final ethanol content in wine would be around $4.4 \%(\mathrm{w} / \mathrm{v})$ and $4.0 \%(\mathrm{w} / \mathrm{v})$ as suggested by Chen et al., 2015 in the $\mathrm{CoH} 160$ and $\mathrm{Co} 89003$ sugarcane varieties, respectively. Raspor and Goranovic (2008) also reported that the alcohol content affects a performance of acetic acid bacteria both in the beginning and at the end of fermentation. Thus, an optimum amount of alcohol is recommended because high initial alcohol concentration decreased the bacterial vitality due to the antimicrobial effect of ethanol. In contrast, if the initial concentration of ethanol was too less $(0.1-0.2 \%)$ it will enhance the risk for overoxidation. The alcohol content in the wine was estimated as per Caputi et al., (1968) method.

\section{Vinegar (Acetous fermentation)}

Wine was subjected to acetic acid fermentation under submerged conditions by the addition of Acetobacter aceti inoculum. Loopful culture of Acetobacter aceti from slants were inoculated in sterilized yeast extract peptone mannitol (YPM) broth and kept for $24 \mathrm{~h}$ at $28^{\circ} \mathrm{C}$ on shaker at 150 rpm. Then broth was added to partially clarified wine to carry out acetous fermentation. Apart from Acetobacter inoculum mother vinegar from cider was also added at $5 \%$ level. Sterile wood shavings were also added at $1 \%$ level which served as platform for Acetobacter cells to grow and helped in reducing time for acetous fermentation. Acidity was periodically measured till constant value was obtained. The acetic acid (\%) in the prepared vinegar was estimated firstly by distillation of a sample and then it was titrated against $0.1 \mathrm{~N}$ sodium hydroxide (Rangana, 2003). Finally, after the filtration, the vinegar was tested for the qualitative parameters. It was pasteurized and stored in ambered coloured bottles for further sensory and quantitative analytical studies (Fig 1). The physico-chemical composition of the vinegar produced is mentioned in the Table 4.

\section{Statistical analysis}

A statistical package design expert version 12 of Response Surface Methodology was applied on the experimental data and different response surface plots were studied. The statistical significance of terms in the regression equation was examined by analysis of variance (ANOVA). To obtain statistical significance three replications of the different variables were taken for the computation study. 


\section{RESULTS AND DISCUSSION} Optimization using RSM design

Three process parameters (inoculum, temperature, time) were used for liquid jaggery vinegar production and were incorporated into optimization RSM software to establish their optimum levels. The CCRD design of three factors was adapted to study the optimum levels and to explicate the effect of these independent variables on acetic acid concentration of the liquid jaggery vinegar. Twenty experimental trials were carried out in randomized order as per the CCRD design. The results are presented in Table 1. The data generated was analyzed using Design Expert Software (12 version) and a present polynomial equation was obtained for the response. The second order equation (Eq. 1) was built to describe the response.

$$
y=b_{o}+\sum_{i} b_{i} x_{i}+\sum_{i} b_{i i} x_{i}^{2}+\sum_{i j} b_{i j} x_{i j} x_{j}
$$

In the above equation, $y$ and $x$ are the response and factor for the above design. On the right hand side $x_{i,} x_{i}^{2}$ and $x_{1} x_{j}$ are the regression coefficient for linear, quadratic and interaction effect, $b$ is coefficient for each term which is being calculated by applying multiple regression analysis and a lack of fit was also calculated using RSM optimization tool. This model is accounted for by coefficient of determination $\left(R^{2}\right)$ which shows the proportion of variability in data and a larger value of $\mathrm{R}^{2}$ which suggests better fit of model data. An adequacy ratio of more than Table $F$ value depicted that the model is adequate. A second order polynomial model was used to develop three dimensional plots and contour graphs which demonstrated the interaction between independent variables and their effect on the acetic acid content as response. The effects of different variables on acetic acid response of liquid jaggery vinegar, prepared as per experimental design are presented in Table 2.

Effect of temperature, time and inoculum on acetic acid concentration in liquid jaggery vinegar of $\mathrm{CoH} 160$ sugarcane variety

The average acetic acid concentration of liquid jaggery vinegar ranged from 0.53 to $3.99 \%$. The lowest acetic acid concentration $(0.5 \%)$ in vinegar was found in the experimental trial 17 , whereas a highest acetic acid $(3.99 \%)$ was achieved in the experimental trial 16 as shown in the

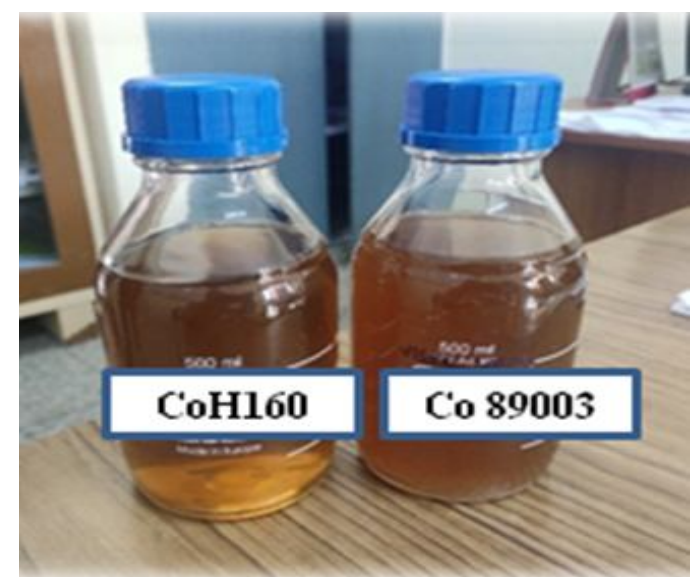

Fig 1: Picture of vinegar produced from liquid jaggery of $\mathrm{CoH}$ 160 and Co 89003.

Table 1: Experimental design for the optimization of experiment as computed using RSM (CoH 160 and Co89003)

\begin{tabular}{|c|c|c|c|c|c|c|}
\hline \multirow[b]{2}{*}{ Std. no. } & \multicolumn{3}{|c|}{ Coded values } & \multicolumn{3}{|c|}{ Actual values } \\
\hline & $\begin{array}{c}\text { Factor } 1 \mathrm{~A}: \\
\text { Temperature }\left({ }^{\circ} \mathrm{C}\right)\end{array}$ & $\begin{array}{l}\text { Factor 2B: } \\
\text { Time (days) }\end{array}$ & $\begin{array}{c}\text { Factor 3C: } \\
\text { Inoculum (\%) }\end{array}$ & $\begin{array}{c}\text { Factor } 1 \mathrm{~A}: \\
\text { Temperature }\left({ }^{\circ} \mathrm{C}\right)\end{array}$ & $\begin{array}{l}\text { Factor 2B: } \\
\text { Time (days) }\end{array}$ & $\begin{array}{r}\text { Factor 3C: } \\
\text { Inoculum (\%) }\end{array}$ \\
\hline 1 & -1 & -1 & -1 & 32.0 & 10.0 & 5.0 \\
\hline 2 & -1 & -1 & -1 & 25.0 & 10.0 & 5.0 \\
\hline 3 & -1 & 1 & -1 & 28.5 & 12.5 & 3.29 \\
\hline 4 & 1 & 1 & -1 & 25.0 & 15.0 & 5.0 \\
\hline 5 & -1 & -1 & 1 & 32.0 & 15.0 & 5.0 \\
\hline 6 & 1 & -1 & 1 & 28.5 & 12.5 & 7.5 \\
\hline 7 & -1 & 1 & 1 & 25.0 & 10.0 & 10.0 \\
\hline 8 & 1 & 1 & 1 & 32.0 & 15.0 & 10.0 \\
\hline 9 & -1.684 & 0 & 0 & 28.5 & 12.5 & 7.5 \\
\hline 10 & 1.684 & 0 & 0 & 25.0 & 15.0 & 10.0 \\
\hline 11 & 0 & -1.684 & 0 & 28.5 & 12.5 & 7.5 \\
\hline 12 & 0 & 1.684 & 0 & 28.5 & 12.5 & 7.5 \\
\hline 13 & 0 & 0 & -1.684 & 28.5 & 16.0 & 7.5 \\
\hline 14 & 0 & 0 & 1.684 & 28.5 & 8.00 & 7.5 \\
\hline 15 & 0 & 0 & 0 & 32.0 & 10.0 & 10.0 \\
\hline 16 & 0 & 0 & 0 & 28.5 & 12.5 & 7.5 \\
\hline 17 & 0 & 0 & 0 & 22.6 & 12.5 & 7.5 \\
\hline 18 & 0 & 0 & 0 & 28.5 & 12.5 & 11.7 \\
\hline 19 & 0 & 0 & 0 & 28.5 & 12.5 & 7.5 \\
\hline 20 & 0 & 0 & 0 & 34.3 & 12.5 & 7.5 \\
\hline
\end{tabular}


Table 2. The maximum acetic acid (3.99\%) was observed at a temperature of $28.5^{\circ} \mathrm{C}$, fermentation period of 12.5 days and $7.5 \%$ inoculum concentration $(\mathrm{CoH} 160)$, while minimum acetic acid $(0.53 \%)$ was observed at $22.61^{\circ} \mathrm{C}$ temperature, 12.5 days fermentation period and $7.5 \%$ inoculum concentration (Table 2 ). The regression equation coefficients were calculated and the data were fitted to a second-order polynomial equation. Thus, to predict acetic acid per cent as affected by different factors which are represented in terms of their actual factors, a multiple regression equation was generated as shown below (Eq. 2):

Acetic acid $(\%)=+3.92+0.44$ *Temperature $+0.03 *$ Time + 0.51 *Inoculum -0.13 *Temperature *Time +0.10 *Temperature ${ }^{*}$ Inoculum + 0.45 *Time *Inoculum -0.94 * Temperature ${ }^{2}-0.49^{*}$

$$
\text { Time }^{2}-0.63 \text { * Inoculum }{ }^{2}
$$

The analysis of variance (ANOVA) depicted the acetic acid as a function of initial values of parameters. Table 3 shows the regression analysis of the data, in which the coefficient of determination $\left(R^{2}\right)$ was found to be 0.985 indicating that the statistical model was significant and can explain the variability in the response. The model $F$ value was found to be 77.75 , which is more than the tabulated $F$ value as indicated in the ANOVA of quadratic model. A minimum desirable adequate precision value (APV) of 4.00 is required for high prediction ability, where in the study it was found to be 24.59 which are higher than the minimum value required. Therefore, the statistical analysis demonstrates that this model can be efficiently applied to explain the effect of independent variables on acetic acid content of the developed vinegar (Table 3).

Effect of temperature, time and inoculum per cent on acetic acid concentration in liquid jaggery vinegar of Co 89003 sugarcane variety

The average acetic acid concentration of liquid jaggery vinegar ranged from 0.41 to $3.73 \%$. The lowest acetic acid concentration $(0.41 \%)$ in vinegar was found in the experimental trial 17 , whereas highest acetic acid $(3.73 \%)$ was achieved in experimental trial 6 as shown in Table 2. The maximum acetic acid $(3.73 \%)$ was observed at a temperature of $28.5^{\circ} \mathrm{C}$, fermentation period of 12.5 days and $7.5 \%$ inoculum concentration (Co 89003 ), while minimum acetic acid $(0.41 \%)$ was observed at $22.61^{\circ} \mathrm{C}$ temperature, 12.5 days fermentation period and $7.5 \%$ inoculum concentration (Table 2 ). The regression equation coefficients were calculated and the data were fitted to a second-order polynomial equation. Thus, to predict acetic acid per cent as affected by different factors which are represented in terms of their actual factors, a multiple regression equation was generated as shown below (Eq. 3):

Acetic acid $(\%)=+3.70+0.44$ *Temperature $+0.02{ }^{*}$ Time+ 0.50 *Inoculum $-0.11{ }^{*}$ Temperature* Time +0.12 *Temperature* Inoculum + $0.44{ }^{*}$ Time * Inoculum - 0.89 *Temperature ${ }^{2}-0.44^{*}$ Time $^{2}-0.56^{*}$ Inoculum ${ }^{2}$

The analysis of variance (ANOVA) depicted the acetic acid as a function of initial values of parameters. Table 3

Table 2: Acetic acid percent of vinegar prepared with different levels of temperature, time and inoculum percent from liquid jaggery of sugarcane varieties $\mathrm{CoH} 160$ and $\mathrm{Co89003.}$

\begin{tabular}{|c|c|c|c|c|c|}
\hline Std. no. & $\begin{array}{c}\text { Factor 1A: } \\
\text { temperature }\left({ }^{\circ} \mathrm{C}\right)\end{array}$ & $\begin{array}{l}\text { Factor 2B: } \\
\text { time (days) }\end{array}$ & $\begin{array}{l}\text { Factor 3C: } \\
\text { inoculum (\%) }\end{array}$ & $\begin{array}{c}\text { Response acetic acid } \\
(\%) \mathrm{CoH} 160\end{array}$ & $\begin{array}{c}\text { Response acetic acid } \\
(\%) \text { Co } 89003\end{array}$ \\
\hline 1 & 32 & 10 & 5 & 2.28 & 2.14 \\
\hline 2 & 25 & 10 & 5 & 1.00 & 1.02 \\
\hline 3 & 28.5 & 12.5 & 3.29 & 1.41 & 1.39 \\
\hline 4 & 25 & 15 & 5 & 0.87 & 0.81 \\
\hline 5 & 32 & 15 & 5 & 1.05 & 0.99 \\
\hline 6 & 28.5 & 12.5 & 7.5 & 3.98 & 3.73 \\
\hline 7 & 25 & 10 & 10 & 1.34 & 1.27 \\
\hline 8 & 32 & 15 & 10 & 3.58 & 3.49 \\
\hline 9 & 28.5 & 12.5 & 7.5 & 3.89 & 3.72 \\
\hline 10 & 25 & 15 & 10 & 2.42 & 2.35 \\
\hline 11 & 28.5 & 12.5 & 7.5 & 3.91 & 3.70 \\
\hline 12 & 28.5 & 12.5 & 7.5 & 3.88 & 3.69 \\
\hline 13 & 28.5 & 16 & 7.5 & 2.35 & 2.29 \\
\hline 14 & 28.5 & 8 & 7.5 & 2.63 & 2.57 \\
\hline 15 & 32 & 10 & 10 & 2.44 & 2.39 \\
\hline 16 & 28.5 & 12.5 & 7.5 & 3.99 & 3.67 \\
\hline 17 & 22.6 & 12.5 & 7.5 & 0.53 & 0.41 \\
\hline 18 & 28.5 & 12.5 & 11.7 & 2.84 & 2.77 \\
\hline 19 & 28.5 & 12.5 & 7.5 & 3.87 & 3.71 \\
\hline 20 & 34.3 & 12.5 & 7.5 & 1.97 & 1.89 \\
\hline
\end{tabular}

Response values are average of three replications. 
Table 3: Regression coefficients and ANOVA of fitted quadratic model for acetic acid percent of liquid jaggery vinegar of sugarcane varieties $\mathrm{CoH} 160$ and $\mathrm{Co} 89003$.

\begin{tabular}{lcc}
\hline \multirow{2}{*}{ Partial coefficients } & \multicolumn{2}{c}{ Sugarcane varieties } \\
\cline { 2 - 3 } & $\begin{array}{c}\text { CoH } 160 \\
\text { acetic acid }\end{array}$ & $\begin{array}{c}\text { Co } 89003 \\
\text { acetic acid }\end{array}$ \\
\hline Intercept & 3.92 & 3.70 \\
A-Temperature & $0.44^{* *}$ & $0.44^{* *}$ \\
B-Time & $0.03^{\mathrm{NS}}$ & $0.02^{\mathrm{NS}}$ \\
C-Inoculum & $0.51^{* *}$ & $0.50^{* *}$ \\
$\mathrm{~A}^{2}$ & $-0.94^{* *}$ & $-0.89^{* *}$ \\
$\mathrm{~B}^{2}$ & $-0.49^{* *}$ & $-0.44^{* *}$ \\
$\mathrm{C}^{2}$ & $-0.63^{* *}$ & $-0.56^{* *}$ \\
AB & $-0.13^{\mathrm{NS}}$ & $-0.11^{\mathrm{NS}}$ \\
AC & $0.10^{\mathrm{NS}}$ & $0.12^{\mathrm{NS}}$ \\
BC & $0.45^{* *}$ & $0.44^{* *}$ \\
Lack of fit & $\mathrm{S}$ & $\mathrm{S}$ \\
Model F value & $77.75^{* *}$ & $85.02^{* *}$ \\
$\mathrm{R}^{2}$ & 0.985 & 0.987 \\
Adequate precision value & 24.59 & 26.05 \\
\hline
\end{tabular}

${ }^{* *} \mathrm{p} \leq 0.01$ and NS non-significant; S- Significant

Table 4: The physico-chemical composition of the vinegar.

\begin{tabular}{lcc}
\hline Parameters & $\mathrm{CoH} 160$ & Co89003 \\
\hline Total soluble solids ( ${ }^{\circ}$ Brix) & $4.75 \pm 0.01$ & $4.55 \pm 0.1$ \\
Reducing sugars (\%) & $0.26 \pm 0.05$ & $0.29 \pm 0.04$ \\
Total sugars (\%) & $2.7 \pm 0.26$ & $2.8 \pm 0.36$ \\
Titratable acidity (\%) & $5.10 \pm 0.17$ & $4.72 \pm 0.05$ \\
$\mathrm{pH}$ & $4.28 \pm 0.06$ & $4.52 \pm 0.03$ \\
Total phenols (mg/100 mL) & $38.22 \pm 0.38$ & $36.69 \pm 0.32$
\end{tabular}

${ }^{*}$ Values are mean \pm S.D of three replicates. shows the regression analysis of the data, in which the coefficient of determination $\left(R^{2}\right)$ was found to be 0.987 indicating that the statistical model was significant and can explain the variability in the response. The model $F$ value was found to be 85.02 , which is more than the tabulated $F$ value as indicated in the ANOVA of quadratic model. A minimum desirable adequate precision value (APV) of 4.00 is required for high prediction ability, where in the study it was found to be 26.05 which are higher than the minimum value required. Therefore, the statistical analysis demonstrates that this model can be efficiently applied to explain the effect of independent variables on acetic acid content of the developed vinegar.

A similar trend was observed for the regression coefficients and ANOVA of fitted quadratic model for acetic acid percent in liquid jaggery vinegar of both the sugarcane varieties ( $\mathrm{CoH} 160$ and $\mathrm{Co} 89003)$. The coefficient estimate of the acetic acid model (Table 3 ) shows that the level of temperature and inoculum at linear terms had highly significant $(p \leq 0.01)$ effect and an increase in temperature and inoculum percent enhanced the acetic acid production in vinegar due to the greater bioconversion of the sugars into alcohol and acetic acid. Similar results were also depicted by Saha and Banerjee, 2013 which have found that acetic acid concentration increased with an increase in an amount of inoculum percent. At 15 and $10 \%$ inoculum concentration, acetic acid concentration of $4.67 \%$ and $4.62 \%$ was observed. Gullo et al., 2014 found that the optimum temperature for the wine vinegar production is $30^{\circ} \mathrm{C}$ whereas the growth of bacteria was inhibited if a temperature was above $35^{\circ} \mathrm{C}$ and below $8^{\circ} \mathrm{C}$. In this study, an optimum temperature was observed at $28.5^{\circ} \mathrm{C}$ for the vinegar production at $7.5 \%$ inoculum level. However, non-significant effect of time was observed on the acetic acid response.

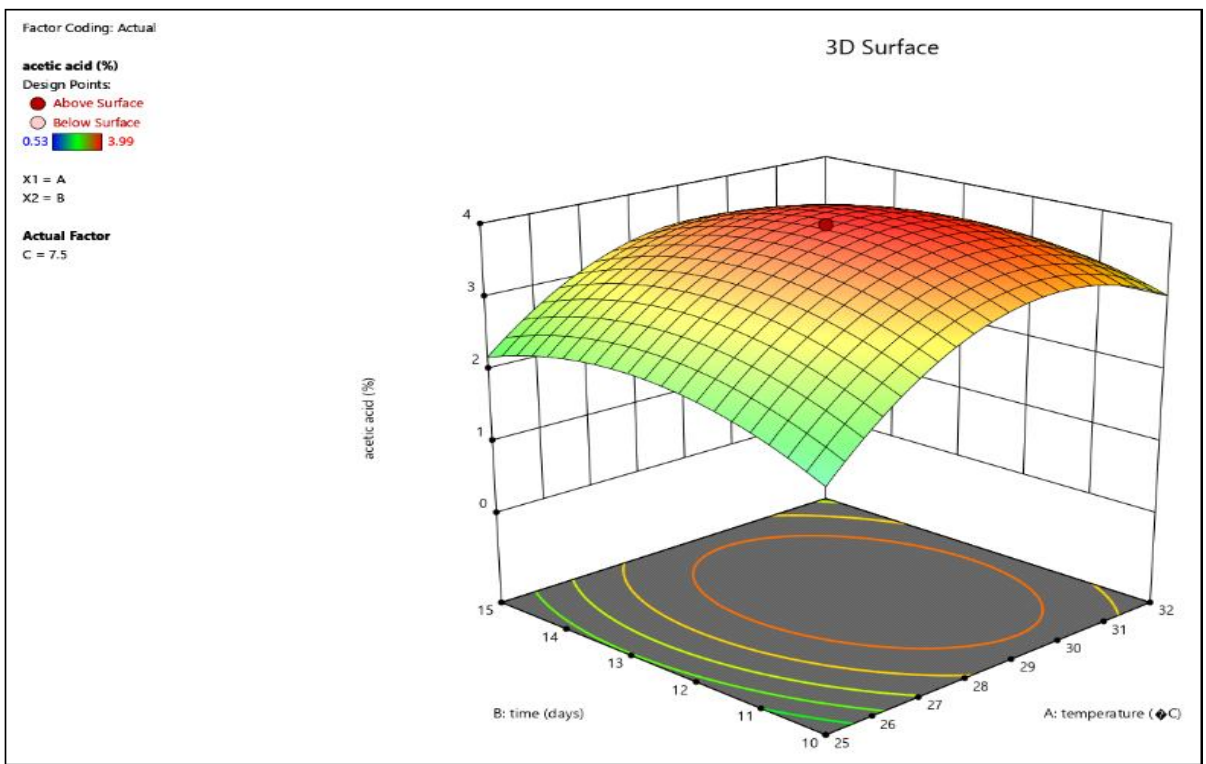

Fig 2: Effect of temperature, time and inoculum on an acetic acid content of the liquid jaggery vinegar prepared from CoH 160 sugarcane variety. 


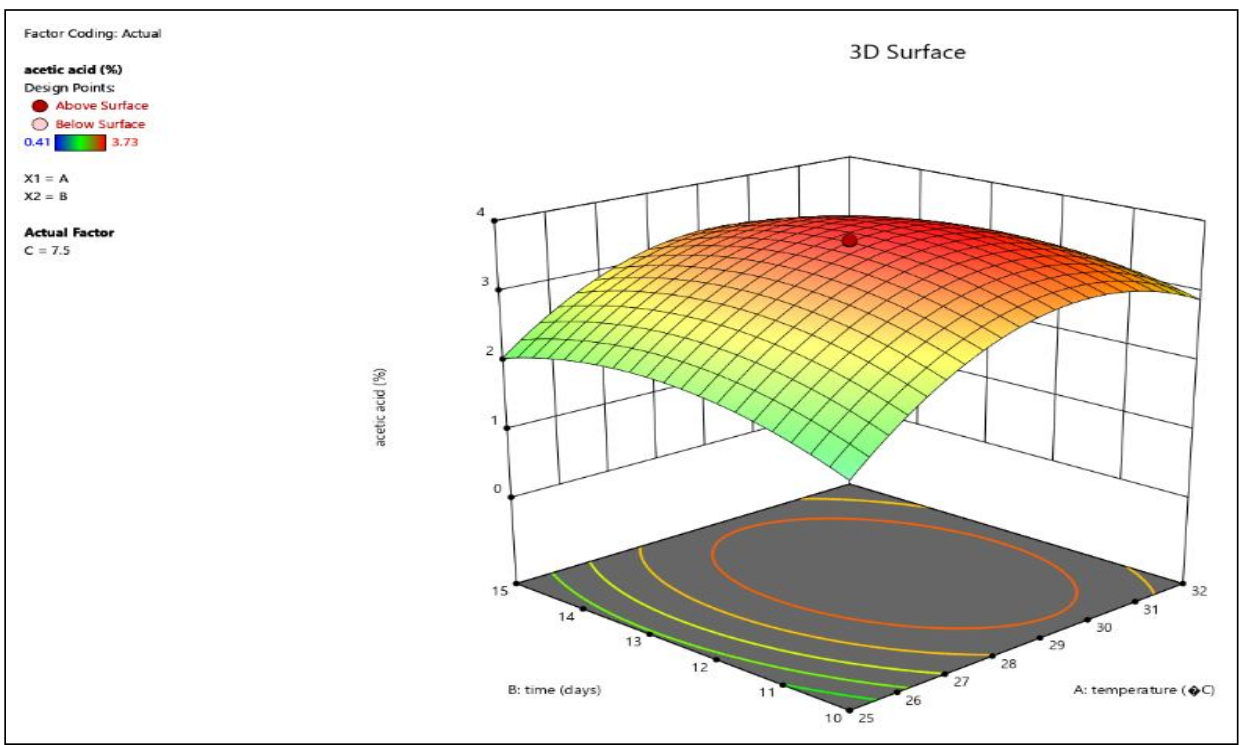

Fig 3: Effect of temperature, time and inoculum on acetic acid content of the liquid jaggery vinegar prepared from Co 89003 sugarcane variety.

The squared terms of temperature, time and inoculum had negative highly significant effect $(p \leq 0.01)$, thus increasing any of these independent factors, decreased the acetic acid concentration in liquid jaggery vinegar. Any of these factors alone, keeping others constant will affect the microbial metabolism in an inverse way. The interaction between the time and inoculum variables also had statistically significant effect $(p \leq 0.01)$ on acetic acid, thus a higher acetic acid concentration was observed when the fermentation period (time) was increased from 10 to 15 days and inoculum percent was increased from 5 to 10 per cent. A similar trend was observed by the Ghosh et al., 2012.

The interaction amongst variables and their effect on acetic acid per cent of vinegar is shown in the three dimensional graph (Fig 2). The acetic acid concentration achieved in the optimum liquid jaggery vinegar prepared from $\mathrm{CoH} 160$ and $\mathrm{Co} 89003$ sugarcane varieties was found to be 3.99 and 3.73 per cent which is in accordance with the acetic acid content of 3.04 per cent as found out by the Chen et al., 2015 in the sugarcane juice vinegar prepared from different yeasts and acetic acid bacteria. Also in both sugarcane varieties maximum acetic acid content in liquid jaggery vinegar was observed at a temperature around $28.5^{\circ} \mathrm{C}$ which is in agreement with Arifuzzaman et al., 2014 which found that all isolated Acetobacter strains were able to grow at $25^{\circ} \mathrm{C}$ and $37^{\circ} \mathrm{C}$ but the most favourable temperature in which a higher potency in terms of acetic acid content was observed at $30^{\circ} \mathrm{C}$. Similar observation was also reported by Sharafi et al., 2010 where the acetic acid production was found to be optimum at temperature of $31^{\circ} \mathrm{C}$. Optimisation of temperature is considered essential for any biotechnological process as the microbial inactivation and enzyme denaturation can occur above the optimum temperature.

The expected response of acetic acid and its correlation between the different independent variables are shown in three dimensional plots (Fig 2 and 3 ), with temperature on
$\mathrm{X}$-axis and time on $\mathrm{Y}$-axis while inoculum percentage was kept $(7.5 \%)$ constant at ' $O$ ' central level. With an increase in temperature, acetic acid concentration increases at first and then decreases. With an increase in the number of days, acetic acid concentration increases at first and then decreases.

\section{CONCLUSION}

Response Surface Methodology can be effectively employed to optimize the process parameters for the development of vinegar from liquid jaggery. The fermented natural vinegar prepared from liquid jaggery contained acetic acid $>3.5 \%$ which is as per FSSAI, 2011 requirements. The optimum levels of inoculum $(7.5 \%)$, temperature $\left(28.5^{\circ} \mathrm{C}\right)$ and time (12.5 days) used during the production of vinegar resulted in an overall acceptable product in context with acetic acid concentration, taste and aroma. The vinegar thus obtained was also adjusted sensorily acceptable.

\section{REFERENCES}

Adebayo-Oyetoro, A.O., Adenubi, E., Ogundipe, O.O., Bankole, B.O. and Adeyeye, S.A.O. (2017). Production and quality evaluation of vinegar from mango. Cogent Food and Agriculture. 3(1): 1278193.

Arifuzzaman, M., Hasan, M.Z., Rahman, S.M.B and Pramanik, M.K. (2014). Isolation and characterization of Acetobacter and Gluconobacter spp from sugarcane and rotten fruits. Research and Reviews in Biosciences. 8(9): 359-365

Caputi, A., Ueda, M. and Brown, T. (1968). Spectrophotometric determination of ethanol in wine. American Journal of Enology and Viticulture. 19(3): 160-165.

Chen, G.L., Zheng, F.J., Sun, J., Li, Z.C., Lin, B. and Li, Y.R. (2015). Production and characteristics of high quality vinegar from sugarcane juice. Sugar Technology. 17(1): 89-93.

FSSAI (2011). Vinegar. In: Compendium. Food Safety and Standards (Food Products Standards and Food Additives) Regulations. 171. 
Ghosh, S., Chakraborty, R., Chatterjee, G. and Raychaudhuri, U. (2012). Study on fermentation conditions of palm juice vinegar by response surface methodology and development of a kinetic model. Brazilian Journal of Chemical Engineering. 29(3): 461-472.

Gullo, M., Verzelloni, E. and Canonico, M. (2014). Aerobic submerged fermentation by acetic acid bacteria for vinegar production: Process and biotechnological aspects. Process Biochemistry. 49(10):1571-1579.

Kocher, G.S., Kalra, K.L. and Phutela, R.P. (2006). Comparative production of sugarcane vinegar by different immobilization techniques. Journal of the Institute of Brewing. 112(3): 264-266.

Kumar, A. and Singh, S. (2020). The benefit of Indian jaggery over sugar on human health. Dietary Sugar, Salt and Fat in Human Health, Academic Press. 347-359.

Nath, A., Dutta, D., Kumar, P. and Singh, J.P. (2015). Review on recent advances in value addition of jaggery based products. Journal of Food Processing Technology. 6(4). doi: 10.4172/2157-7110.1000440.

Oliveira, É.R., Caliari, M., Júnior, M.S.S. Oliveira, A.R., Duarte, R.C.M and Boas, E.V.B.V. (2018). Assessment of chemical and sensory quality of sugarcane alcoholic fermented beverage. Journal of Food Science and Technology. 55(1): 72-81.
Ranganna, S. (2003). Handbook of Analysis and Quality Control for Fruit and Vegetable Products. Tata McGraw Hills Publishing Co. Ltd., New Delhi.

Raspor, P. and Goranovič, D. (2008). Biotechnological applications of acetic acid bacteria. Critical Reviews in Biotechnology. 28: 101-124.

Ribeiro, L.S., Duarte, W.F., Dias, D.R. and Schwan, R.F. (2015). Fermented sugarcane and pineapple beverage produced using Saccharomyces cerevisiae and non-Saccharomyces yeast. Journal of the Institute of Brewing. 121: 262-272.

Saha, P. and Banerjee, S. (2013). Optimization of process parameters for vinegar production using banana fermentation. International Journal of Research in Engineering and Technology. 2(9): 501-514.

Snedecor, G.W. and Cochran, W.G. (1967). Statistical Methods, $6^{\text {th }}$ edn. Oxford and IBH Pub Co, New Delhi, pp 234-257.

Sharafi, S., Rasooli, I. and Beheshti-Maal, K. (2010). Isolation, characterization and optimization of indigenous acetic acid bacteria and evaluation of their preservation methods. Iranian Journal of Microbiology. 2(1): 38-45.

Singh, J., Singh, R.D., Anwar, S.I. and Solomon, S. (2011). Alternative sweeteners production from sugarcane in India: Lump Sugar (jaggery). Sugar Tech. 13(4): 366-371. 